\title{
Real-world response of COVID-19 patients in Mexico.
}

Gilberto González Arroyo, BS, MS ${ }^{1,2}$, Salvador Gómez García, MD, MS ${ }^{3}$, Anel Gómez García, $\mathrm{PhD}^{4}$, Adán Pacifuentes Orozco ${ }^{5}$, Jorge Gustavo González Orozco, $\mathrm{MD}^{6}$, Maricela García Arreola, $\mathrm{MD}^{6}$, Karla Guadalupe López López, MD, $\mathrm{MS}^{3}$, Tonatihu Ortiz Castillo, MD, $\mathrm{MS}^{3}$, Noga Or-Geva, $\mathrm{PhD}^{7}$, Sonia Moreno-Grau, $\mathrm{PhD}^{2,8}$, Cleto Álvarez Aguilar, MD, MS ${ }^{1}$, Carlos D. Bustamante, $\mathrm{PhD}^{2,8,10}$, Arturo López Pineda, $\mathrm{PhD}^{1,2, *}$

1. Amphora Health, Morelia, Michoacan, Mexico

2. Galatea Bio Inc, Miami, Florida, USA

3. Decentralized Administrative Operation Body, Mexican Institute for Social Security (IMSS), Monterrey, Nuevo Leon, Mexico

4. Biomedical Research Center of Michoacan, Mexican Institute for Social Security (IMSS), Morelia, Michoacan, Mexico

5. Hospital General Regional No. 1, Charo. Decentralized Administrative Operation Body, Mexican Institute for Social Security (IMSS), Morelia, Michoacan, Mexico

6. Decentralized Administrative Operation Body, Mexican Institute for Social Security (IMSS), Morelia, Michoacan, Mexico.

7. Department of Neurology, Stanford University, Stanford, California, USA

8. Department of Biomedical Data Science, Stanford University, Stanford, California, USA

9. Faculty of Medicine. Michoacan University of Saint Nicholas of Hidalgo (UMSNH), Morelia, Michoacan, Mexico

10. Chan Zuckerberg Biohub, San Francisco, California, USA

*Corresponding author

Address correspondence to:

Dr. Arturo Lopez Pineda (arturo@amphorahealth.com)

Amphora Health

Batallón Independencia 80, Chapultepec Norte 58260, Morelia, México

Phone: +52 4433046300 


\section{Abstract}

Currently in Mexico, the available clinical guidelines published for COVID-19 treatment recommend symptom treatment and home isolation for mild forms; and other medications for severe and acute forms. The effectiveness of how real-world treatment patterns impact mortality and recovery is still unknown. In this retrospective observational study, we investigated 5,575 medicated patients with COVID-19 treated at two Mexican states seen in the largest healthcare system in Mexico. A survival analysis was performed using death and discharge as primary and secondary outcomes (respectively). Machine learning models were built to predict mortality and discharge. The higher prevalence of obesity, diabetes, and heart disease comorbidities is consistent with Mexico's epidemiological profile. Mortality occurs around 15-20 days from the start of symptoms. Antivirals in combination with antibiotics present lower survival rates, with patients undertaking neuraminidase inhibitors (NAIs) being the most affected. Our findings recommend against using specific treatment combinations with NAIs, and should help improve the country's clinical guidelines.

Keywords: COVID-19 drug treatment, Pragmatic Clinical Trials, Machine Learning, Mexico 


\section{Introduction}

The clinical and epidemiological characteristics of patients with COVID-19 have been well described [1], showing that SARS-Cov-2 infection can vary from mild infection without clinical manifestations, to severe infections and even fatal pneumonias, associated with admission to intensive care units and high mortality worldwide [2]. The clinical manifestations include fever, cough, headache, sputum, dyspnea, nasal congestion, fatigue, diarrhea, and recently anosmia and ageusia [3].

The Centers for Disease Control and Prevention (CDC) in its Coronavirus Disease 2019 (COVID-19) report identified some risk to develop severe forms of the disease when the patient presents asthma, chronic obstructive lung disease, diabetes, severe heart disease, kidney disease chronic, severe obesity, age older than 65 years, immunocompromised people, liver disease, among others, and gives a series of recommendations for its prevention and protection [4]. In the early days of the pandemic in March 2020, initial reports suggested that hypertension, diabetes, and cardiovascular disease were the most common comorbidities in affected patients, and case fatality rates tend to be higher in these individuals [5,6]. However, risk factors associated with severe forms of COVID-19 are not yet well understood.

Currently, the management of this disease has focused on controlling the source of infection through social isolation, use of personal protection precautions to reduce the risk of transmission; and early diagnosis, isolation, and supportive treatments for affected patients [7]. Among the drugs used to combat COVID-19 infection, there are different alternatives that were administered due to their ability to interfere with the mechanisms of entry, virus replication and/or the host's immunopathological response. For example, because IL-6 can play an important role in the fight against COVID-19 infection, due to its pleiotropic role in the entire immune system, the addition of azithromycin has been proposed as a treatment to reduce the storm of cytokines caused by COVID-19 virus infection [8]. The apparent mechanism of action is due to the immunomodulatory activity of azithromycin by blocking IL-6 and TNF-alpha.

The pandemic dimensions of SARS-CoV-2 [9], and the emergence of new strains [10] has already affected more than 53.7 million people in the world and is the cause of more than 5.2 million deaths in the world until December 06, 2021 [13]. In particular, the case fatality rate 
observed in Mexico is among the highest worldwide (7.6\% vs 2.1\% worldwide) [11]. Although the vaccination program was announced in December 2020 by the country's officials [12], the reality has been of a slow immunization coverage of the full vaccination scheme (at least two).

At the moment, there are promising drugs for effective treatment of severe forms of the COVID-19 disease. The emergence of novel strains [13] creates uncertainty about the best way to treat these patients. Following guidance from PAHO, government officials in Mexico published interim management guidelines based on the little known evidence worldwide. The first guideline was published on April 7, 2020, where the use of hydroxychloroquine, azithromycin, steroid, human immunoglobulin, interferon beta b1, IL-6 inhibitor and JAK inhibitor were suggested prior to clinical evaluation [14]; On June 25, 2020, the guideline was updated to focus on evaluating the use of complementary therapies such as convalescent plasma, monoclonal antibodies (tocilizumab), steroids (methylprednisolone or dexamethasone), human immunoglobulin, protein-kinase inhibitors [15]. Subsequently, the guideline was updated again on September 25, 2020 where the use of these therapies was suggested under research protocols and to support the management of comorbidities [16]. Studies using hydroxychloroquine did not observe beneficial prophylactic effects [17], nor in hospitalized patients with positive SARS-Cov-2 COVID-19 infection hospitalized using hydroxychloroquine alone [18], or in combination [19], no improvement was observed or less time in hospitalizations. Similar results were obtained with the use of convalescent plasma in patients with severe pneumonia secondary to SARS-CoV-2 COVID-19 [20]. Other treatments under experimentation include neutralizing antibodies [21] and the use of B-1A cells [22] as a therapeutic potential in SARS-CoV-2 COVID-19 patients; however, additional studies are required to verify its effectiveness.

The information contained in the guidelines represents a compilation of the evidence that has emerged in relation to the SARS-CoV-2 COVID-19 pandemic, and it is known by the health authorities and professionals that the information is evolving rapidly. Therefore, health professionals are always advised to use their best clinical judgment when considering the individual patient characteristics, signs and symptoms. In real-world practice, this translates into a large spectrum of potential therapies and combinations that are being used. Evaluating these treatments is of critical importance moving forward to establish the best path forward in the pandemic. 


\section{Materials and Methods}

\section{Study design}

This was a retrospective electronic cohort study to analyze the effect of real-world treatments in COVID-19 patients seen at the Mexican Institute for Social Security (Instituto Mexicano del Seguro Social, IMSS), the largest healthcare provider in Mexico. The patients were seen at IMSS facilities between March 1st, 2020 and March 1st, 2021 in two states, Michoacan (West) and Nuevo Leon (North). IMSS employs a National Biosurveillance System for Infectious Diseases (Sistema Nacional de Vigilancia Epidemiológica, SINOLAVE), which collects relevant information of patients, including demographics, initial symptoms, comorbidities, testing procedures and results, initial medication intake, mortality, and discharge.

Our study has two components, first we aimed to understand the various treatment patterns used to treat COVID-19 patients, evaluating their performance with mortality as the main outcome and recovery as a secondary outcome. Secondly, we then build two machine learning (ML) models to predict the mortality or recovery of a patient given the available data at a given time point of disease progression (10, 20, and 30 days after admission).

A diagram of our study design is shown in Figure 1. Our analysis was run using the $\mathrm{R}$ programming language with multiple libraries, which are displayed in a public repository (https://github.com/AmphoraHealth/covid19). Institutional Review Board (IRB) approval was obtained by IMSS National Bioethics Committee and IMSS National Research Committee, under protocol numbers R-2021-1912-014, R-2020-785-058. The STROBE statement [23] is provided in Supplementary Material A. 


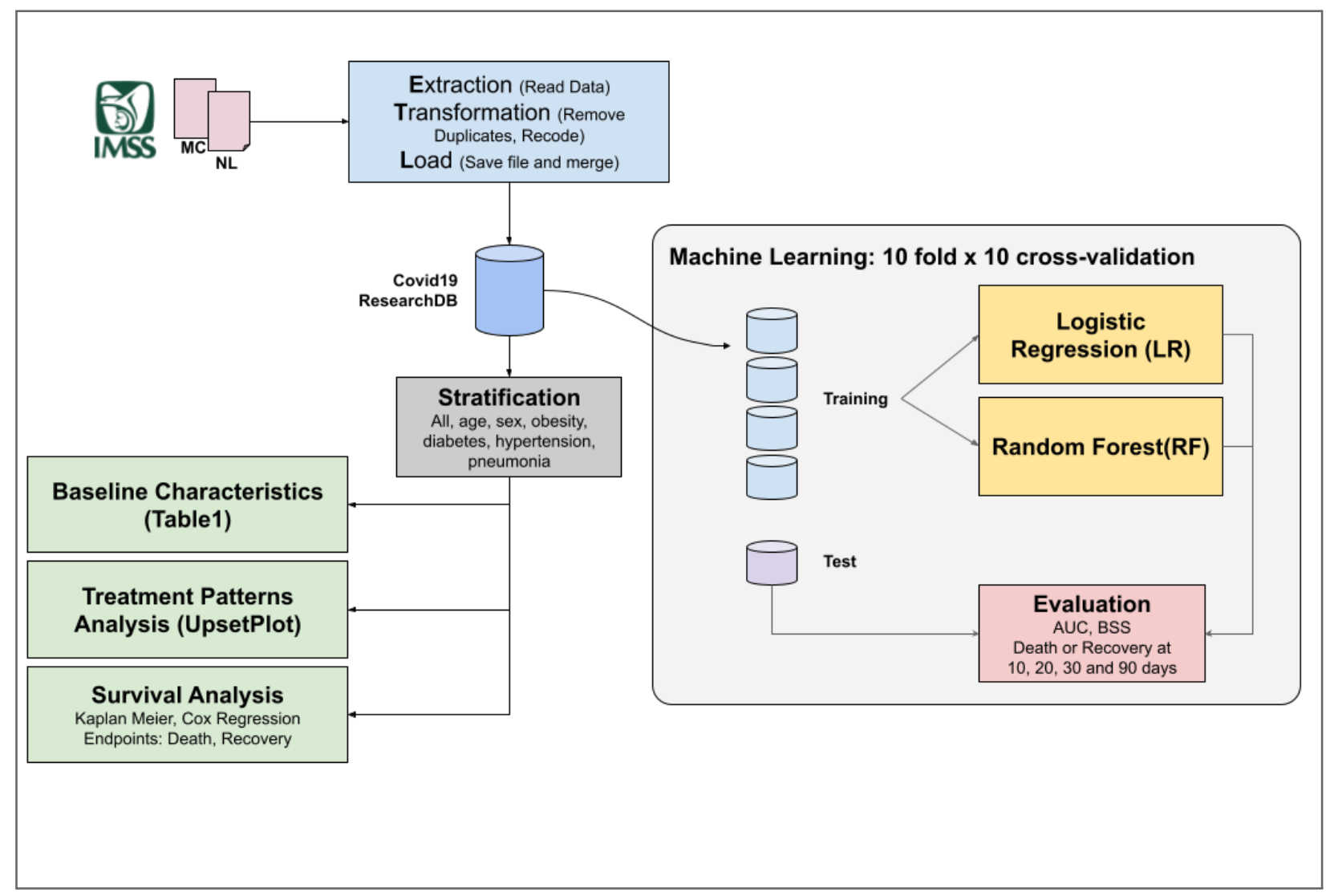

Figure 1. Study design of the Covid19 data (blue), survival analysis (green), and machine learning modeling (yellow).

\section{Data Sources}

SINOLAVE was originally developed for the influenza pandemic of 2009, and it has been quickly evolving to include new variables that are specific to COVID-19, while keeping all those that are also relevant for influenza. De-identification was done by co-author SGG, using the linkage method. Name, last names, and Social Security Number (SSN) were used. All other co-authors did not have access to identifiable information. We filtered the data to select the COVID-19 patients only, which were diagnosed either by a PCR test, or by rapid antigen testing.

The database includes the information about comorbidities, initial symptoms and drugs taken, also the dates of start of the clinical picture, admission and discharge. Medication prescription is recorded in SINOLAVE in three categories: antibiotics, antivirals, and antipyretics. We used the first two categories only, since almost all patients were taking some form of antipyretic. The 
information is structured and registered at each site using structured vocabulary. All drugs are reported in categories described in Supplementary Material B. All missing data was considered to be missing completely at random (MCAR), which is a reasonable assumption for observational studies and the potential loss to follow-up for a variety of reasons.

\section{Statistical analysis}

We calculated the cohort's baseline characteristic for the COVID-19 positive patients, including those with antibiotic and antiviral prescriptions. We created a frequency table from the reported treatments in the database, including combinations of antibiotics and antivirals. The treatments (alone or in combination) included in the subsequent analyses were those that had at least 10 patients taking them. Time zero for these analyses was the start day of clinical symptoms.

A survival analysis and recovery analysis comparing the most common treatments was run with the confirmed COVID-19 patients in the database. The Kaplan-Meier method was used in both cases, and to reduce bias in the analysis we stratified the database using six variables (age group, sex, obesity, diabetes, hypertension and pneumonia). We followed guidance by McCaw et al. [24] on how to code our information to improve survival/recovery predictions using real-world data. Therefore, we assumed that the patient was alive if no mention of death was provided during the duration of the study time span. Similarly, we assumed a patient was still hospitalized unless there was a specific mention for discharge labeled as 'improvement' (other possible cause of discharge is 'death'). Therefore none of the patients were censored in these analyses.

A cox proportional hazard model was built using the following covariates: age group, sex, hospitalization status, initial symptoms and comorbidities. Odds ratio for these variables were also computed using a linear model. To reduce potential sources of bias, we stratified the dataset by the most common comorbidities (i.e. diabetes, obesity, hypertension, coronary heart disease, and pneumonia), and we also created a time-window dataset to minimize potential time-related biases. 
medRxiv preprint doi: https://doi.org/10.1101/2021.12.16.21267866; this version posted December 17, 2021. The copyright holder for this preprint (which was not certified by peer review) is the author/funder, who has granted medRxiv a license to display the preprint in perpetuity.

It is made available under a CC-BY-NC-ND 4.0 International license .

\section{Machine learning}

We build logistic regression and random forests models to predict the outcome of the patient (death or recovery) at 10, 20, and 30 days after the start of first symptoms (day zero). We evaluated these classification tasks using the area under the receiver operating characteristic (AUC) with a 95\% confidence interval (CI). The brier skill score [25] was used to test the calibration of these models, because it provides an index between -1 (not calibrated) and +1 (calibrated).

\section{Results}

The dataset consisted of 130,216 COVID-19 patients with a positive real-time polymerase chain reaction (RT-PCR) test of SARS-CoV-2 (97\%) or by clinical diagnosis of COVID-19 (3\%). We encountered a small number of duplicates in the data which were removed from the analysis. Table 1 summarizes the baseline characteristics, comorbidities and outcomes for these patients.

Table 1. Baseline characteristics

\begin{tabular}{|c|c|c|c|}
\hline & $\begin{array}{c}\text { All Covid }+ \\
\text { patients }\end{array}$ & $\begin{array}{c}\text { Patients taking } \\
\text { antivirals AND/OR } \\
\text { antibiotics }\end{array}$ & $\begin{array}{l}\text { Patients taking } \\
\text { antivirals AND } \\
\text { antibiotics }\end{array}$ \\
\hline $\mathbf{N}$ & $130,216(100 \%)$ & $5,575(100 \%)$ & $955(100 \%)$ \\
\hline $\begin{array}{l}\text { Sex } \\
\quad \text { Female } \\
\text { Male }\end{array}$ & $\begin{array}{l}66,445(51 \%) \\
63,771(49 \%)\end{array}$ & $\begin{array}{l}2,495(45 \%) \\
3,080(55 \%)\end{array}$ & $\begin{array}{l}380(40 \%) \\
575(60 \%)\end{array}$ \\
\hline $\begin{array}{l}\text { Age } \\
\quad<20 \\
{[20,40)} \\
{[40,60)} \\
>60\end{array}$ & $\begin{array}{c}6,654(5 \%) \\
60,611(47 \%) \\
43,537(33 \%) \\
19,414(15 \%)\end{array}$ & $\begin{array}{c}114(2 \%) \\
1,488(27 \%) \\
2,027(36 \%) \\
1,946(34 \%)\end{array}$ & $\begin{array}{c}5(<1 \%) \\
131(14 \%) \\
360(38 \%) \\
459(48 \%)\end{array}$ \\
\hline $\begin{array}{l}\text { Comorbidities } \\
\text { Hypertension | Obesity | Diabetes | Cardiovascular } \\
\text { COPD | Asthma | Smoking History } \\
\text { Renal failure | Chronic hepatic disease } \\
\text { Immunosuppression | HIV | TB | Cancer } \\
\text { Neurological }\end{array}$ & $\begin{array}{c}36,808(28 \%) \\
10,509(8 \%) \\
2,464(2 \%) \\
1,746(1 \%) \\
159(<1 \%)\end{array}$ & $\begin{array}{c}2,949(53 \%) \\
625(11 \%) \\
300(5 \%) \\
128(2 \%) \\
11(<1 \%)\end{array}$ & $\begin{array}{c}635(66 \%) \\
94(10 \%) \\
50(5 \%) \\
24(3 \%) \\
2(<1 \%)\end{array}$ \\
\hline $\begin{array}{l}\text { Complications } \\
\text { Pneumonia }\end{array}$ & $5,409(4 \%)$ & $2,128(38 \%)$ & $429(45 \%)$ \\
\hline Death events & $11,132(9 \%)$ & $1,724(31 \%)$ & $461(48 \%)$ \\
\hline
\end{tabular}

Out of these patients, only 2,746 were taking an antiviral and/or an antibiotic drug. Figure 2 shows the antibiotics and antivirals prescribed to this population (alone or in combination). Fluoroquinolones were the largest group of antibiotics prescribed, while neuraminidase 
medRxiv preprint doi: https://doi.org/10.1101/2021.12.16.21267866; this version posted December 17, 2021. The copyright holder for this preprint (which was not certified by peer review) is the author/funder, who has granted medRxiv a license to display the preprint in perpetuity.

It is made available under a CC-BY-NC-ND 4.0 International license .

inhibitors (NAIs) were the most frequent antivirals. Figure 3 shows the odds ratio from the demographic and symptoms variables (panel A) and from the treatments (panel B), using mortality as the endpoint. We highlighted those covariates with a more significant $p$-value.

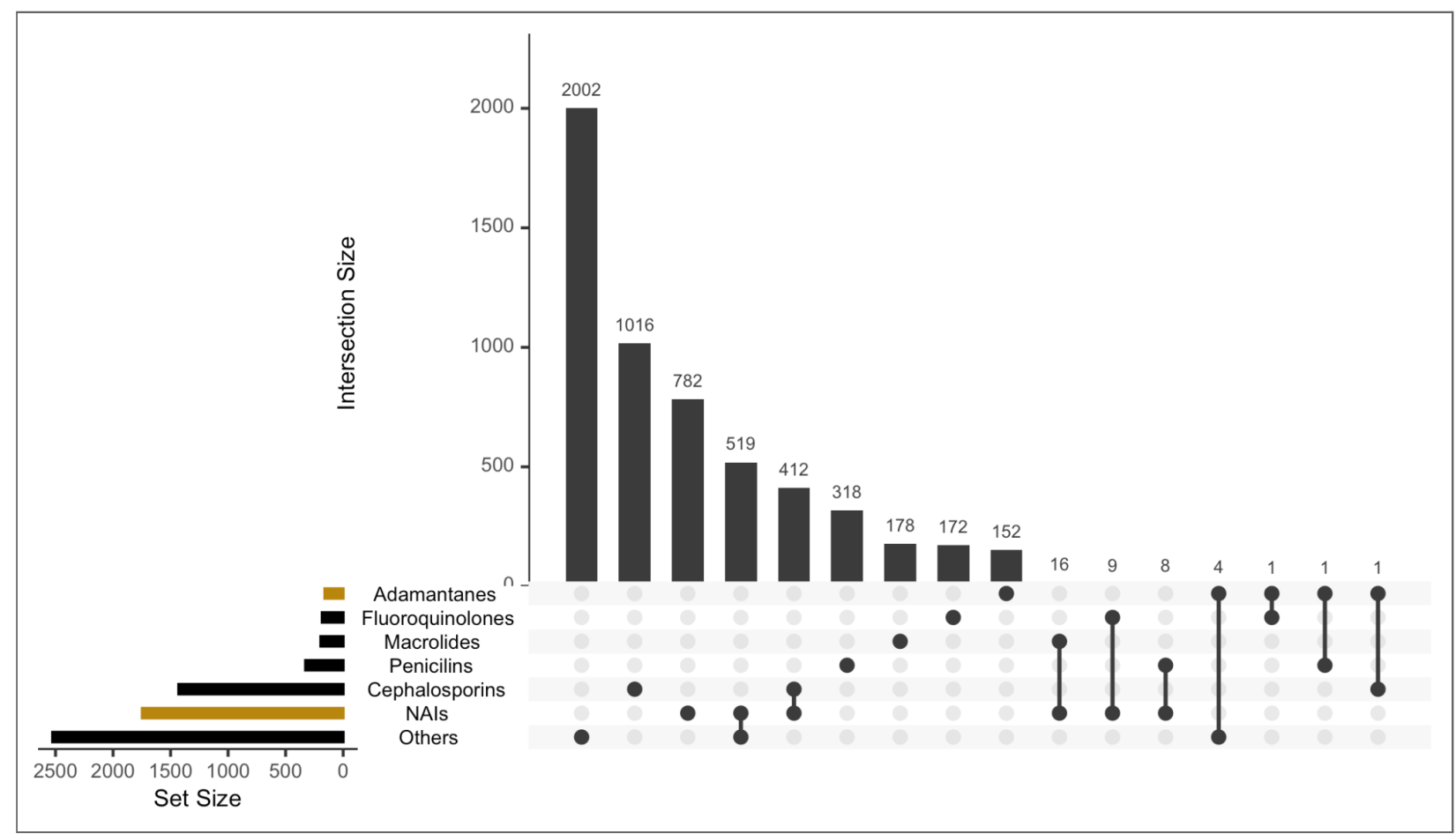

Figure 2. Medication frequency upset plot. Principal treatments patterns in COVID-19 patients from IMSS. A line between two dots indicates the combination of one type of antiviral (gold) with one type of antibiotic (black). NAIs: neuraminidase inhibitors 
medRxiv preprint doi: https://doi.org/10.1101/2021.12.16.21267866; this version posted December 17, 2021. The copyright holder for this preprint (which was not certified by peer review) is the author/funder, who has granted medRxiv a license to display the preprint in perpetuity.

It is made available under a CC-BY-NC-ND 4.0 International license .

A)

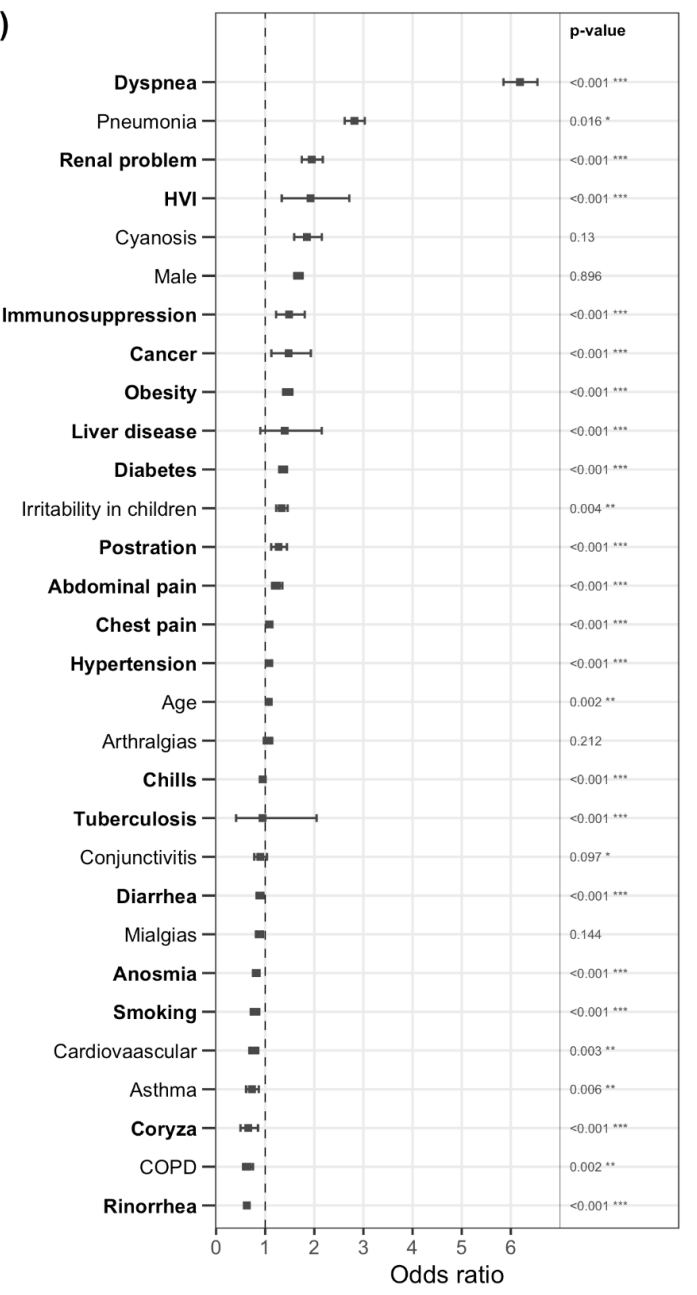

B)

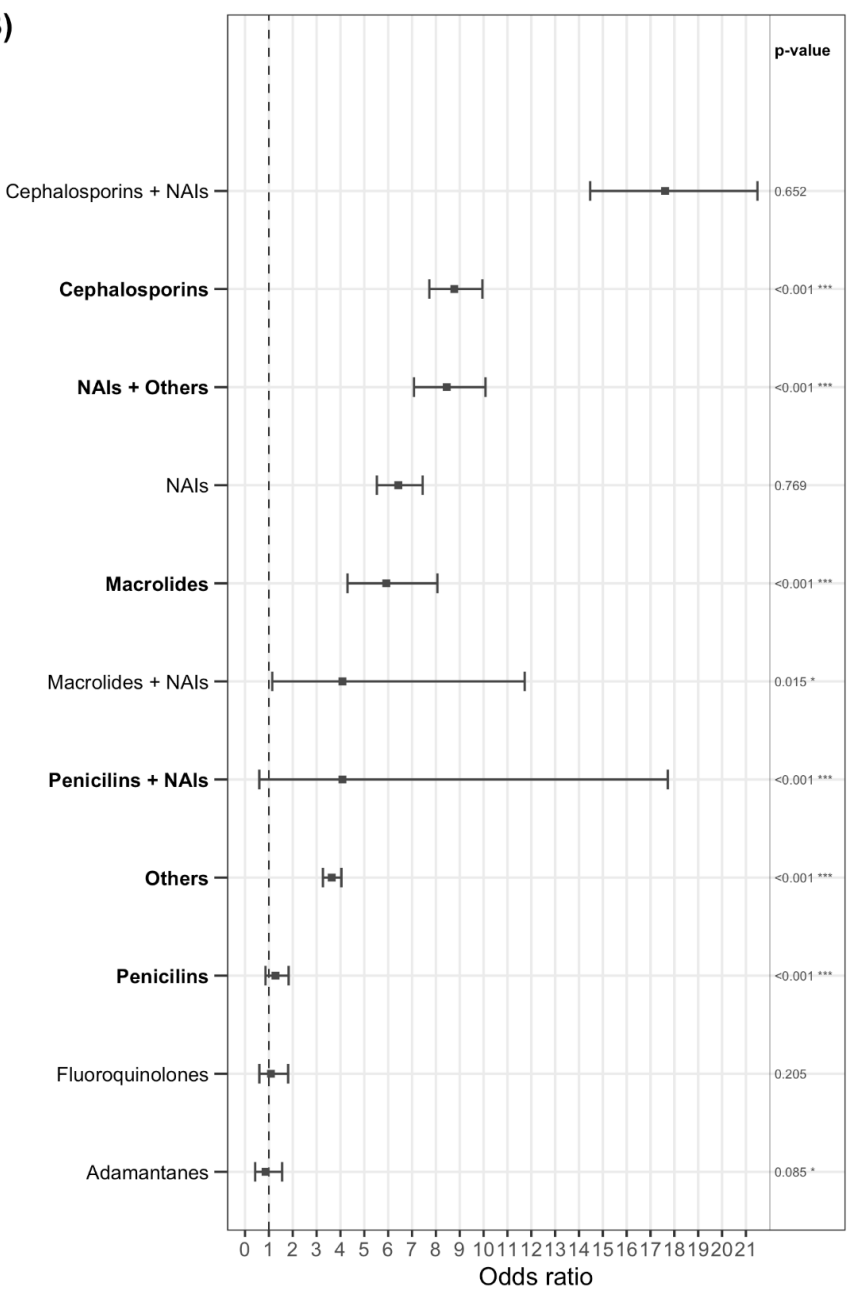

Figure 3. Forest plot: A) Symptoms, age and sex, B) Type of treatment. Most statistically significant variables in each method were highlighted.

The survival and recovery analysis are shown in Figures 4 and 5 respectively, we stratified by different cofactors (hypertension, age groups, diabetes, sex). We found out that the use of neuraminidase inhibitors (NAIs) in combination with Cephalosporins show a lower survival and recovery rate compared to the other treatment patterns. Meanwhile, the use of penicillins have the same or better survival and recovery than those patients not taking any antibiotic or antiviral. 
medRxiv preprint doi: https://doi.org/10.1101/2021.12.16.21267866; this version posted December 17, 2021. The copyright holder for this preprint (which was not certified by peer review) is the author/funder, who has granted medRxiv a license to display the preprint in perpetuity.

It is made available under a CC-BY-NC-ND 4.0 International license .
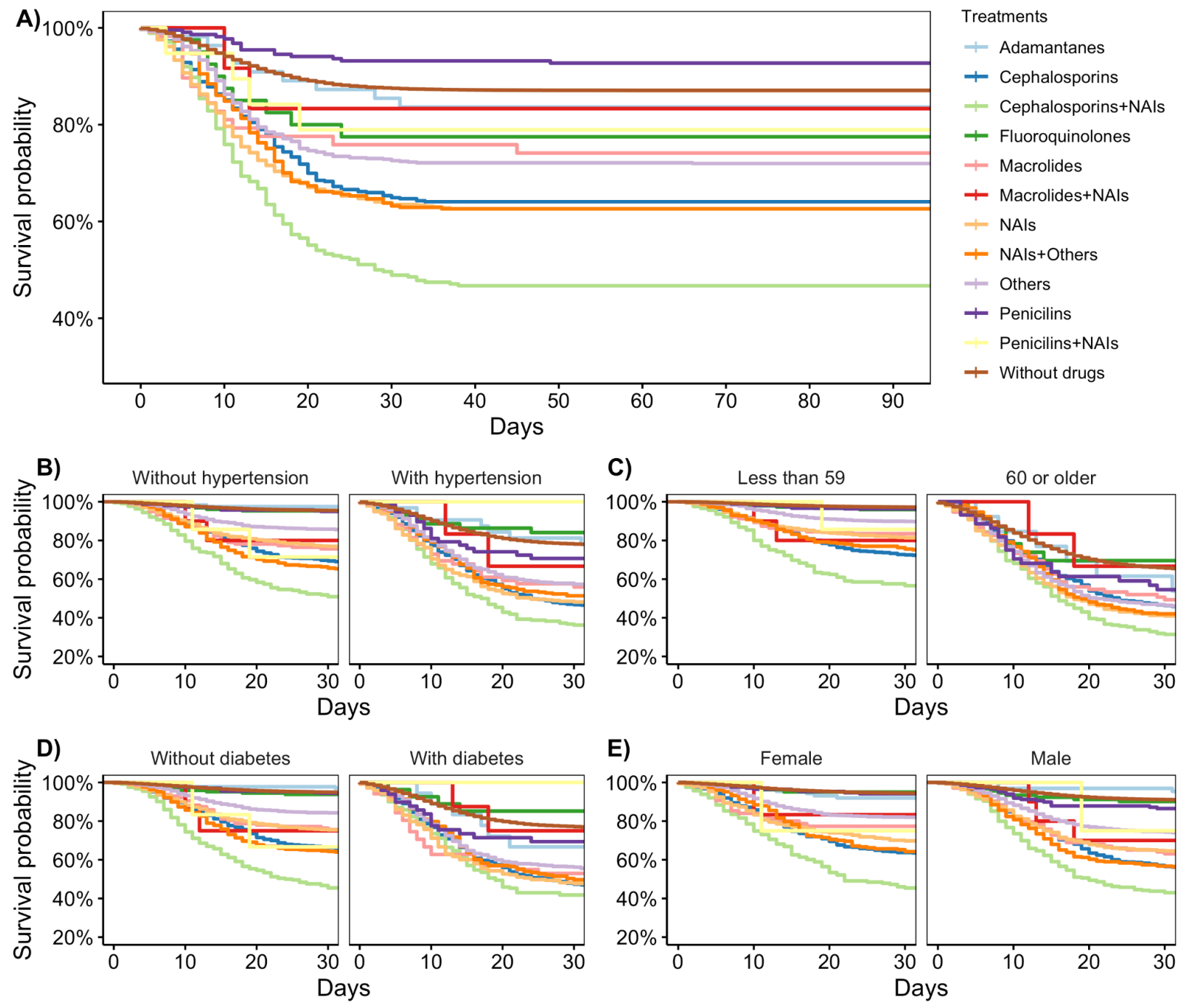

Figure 4. Survival curves. The panels show A) overall survival for the entire cohort, and overall survival (OS) stratified by cofactors B) hypertension, C) age groups, D) diabetes, E) sex. Colors represent the different treatments. 
medRxiv preprint doi: https://doi.org/10.1101/2021.12.16.21267866; this version posted December 17, 2021. The copyright holder for this preprint (which was not certified by peer review) is the author/funder, who has granted medRxiv a license to display the preprint in perpetuity.

It is made available under a CC-BY-NC-ND 4.0 International license .
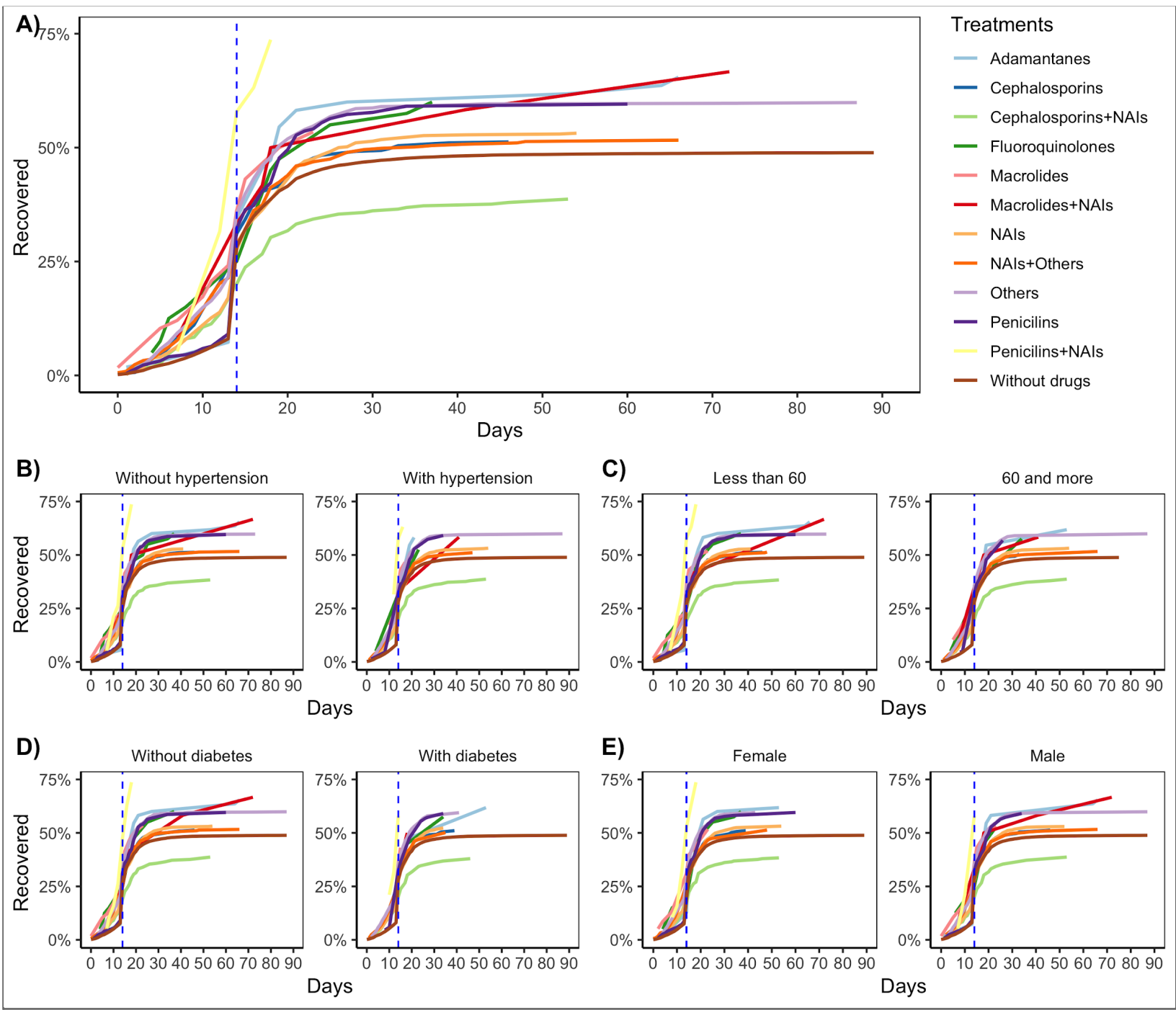

Figure 5. Recovery curves. The panels show A) overall recovery for the entire cohort, and OS stratified by cofactors B) hypertension, C) age groups, D) diabetes, E) sex. Colors represent the different treatments. A dashed line was added on the 14th day representing the default value of recovery for outpatients.

Contrasting with logistic regression (LR) having an average AUC of 0.85 versus the random forest (RF) with an average AUC of 0.92 the random forest model showed a good performance when predicting mortality. The prediction accuracy improved while we relaxed the time window used (i.e. 10, 20, 30 days). All models were calibrated (larger than 0). In contrast, our models had a lower prediction power when predicting recovery in the same cohort, with LR achieving an average AUC of 0.69 , and RF with an average AUC of 0.79 . 
medRxiv preprint doi: https://doi.org/10.1101/2021.12.16.21267866; this version posted December 17, 2021. The copyright holder for this preprint (which was not certified by peer review) is the author/funder, who has granted medRxiv a license to display the preprint in perpetuity.

It is made available under a CC-BY-NC-ND 4.0 International license .

Table 2. AUROC curves. The vaarea under the receiver operating characteristic (AUROC), the $95 \%$ confidence intervals (C.I.) and the Brier Skill Score (BSS) for each case is shown.

\begin{tabular}{|l|c|c|c|c|c|c|}
\hline Classification task & \multicolumn{3}{|c|}{ Logistic regression } & \multicolumn{3}{c|}{ Random forest } \\
\hline Mortality & AUC & $\mathbf{9 5 \%}$ CI & BSS & AUC & $\mathbf{9 5 \% ~ C I ~}$ & BSS \\
\hline Death within 10 days & 0.83 & $0.83-0.84$ & 0.09 & 0.91 & $0.91-0.92$ & 0.30 \\
\hline Death within 20 days & 0.85 & $0.85-0.85$ & 0.20 & 0.91 & $0.91-0.92$ & 0.38 \\
\hline Death within 30 days & 0.86 & $0.85-0.86$ & 0.23 & 0.92 & $0.91-0.92$ & 0.40 \\
\hline Recovery & AUC & $\mathbf{9 5 \%}$ CI & BSS & AUC & $\mathbf{9 5 \%}$ CI & BSS \\
\hline Recovered within 10 days & 0.57 & $0.57-0.58$ & -0.01 & 0.77 & $0.77-0.78$ & 0.15 \\
\hline Recovered within 20 days & 0.66 & $0.65-0.66$ & 0.08 & 0.77 & $0.76-0.77$ & 0.21 \\
\hline Recovered within 30 days & 0.69 & $0.68-0.69$ & 0.10 & 0.79 & $0.79-0.79$ & 0.24 \\
\hline
\end{tabular}

\section{Discussion}

On the prevalence of diabetes, obesity and hypertension in the context of Covid19. The COVID-19 infection very rapidly reached pandemic conditions [26] during 2021 and continued throughout 2021. Several studies have associated chronic diseases such as obesity, diabetes, hypertension and chronic kidney disease (CKD), among others, [27, 28] with the development of severe forms of COVID-19 infection, including pneumonia. Mexico is the third place in the world for deaths attributed to COVID-19 infection and with high prevalence of these chronic kidney diseases [29]; therefore, these comorbidities could be associated with the morbidity and mortality from COVID.-19 in Mexico.

On the access to medications at IMSS and treatment algorithms. The resources and policies available for IMSS clinicians rapidly evolved during the pandemic emergence. As mentioned in the Introduction Section, the guidance offered by the Ministry of Health $(\mathrm{MoH})$ quickly adapted to the global knowledge available at the time. Symptomatic patients with cough, fever, disnea, or cephalea were quickly followed by a more thorough investigation including a PCR or antigen test and other laboratory testing. However, due to the limited resources available in a public healthcare system, access to clinical trials investigational drugs was limited. Furthermore, it was unclear at the time the effect any drug or treatment would have given this new virus. Although the vaccination program officially started in January 2021 in Mexico with the healthcare workers, the effects of this vaccination program were not observed in our data (cutoff in March 2021). 
On the relevant cofactors affecting survival. At the present study, we observed that patterns of medication differ when different scenarios were considered (i.e. diabetes, hypertension, age, sex), even when studied treatments did not present known contraindications for the population subgroups investigated. The impact of medication on survival outcomes is complex in a real-life scenario. Several cofactors might influence it, and several reasons could explain these findings. First, it should be considered the impact of pre-existing comorbidities in response to the infection, and to the target treatment. Age and age-related diseases, including diabetes type 2, obesity and cardiometabolic diseases, are well-known risk factors of COVID-19 severity [30, 31, 32]. These conditions are associated with a chronic inflammatory state [33], and with reduced innate and adaptive immune responses $[34,35]$. In fact, these population subgroups have also been associated with lower survival to influenza virus [36]. Thus, the patient's medical history, as well as the intrinsic individual variability in response to medication, or the pharmacogenomic profile, are relevant cofactors influencing individual medication patterns. In addition, patients with multiple comorbid illnesses might be taking multiple medications, i.e. they might present higher rates of polypharmacy. The potential effect of drug-drug interactions (DDIs) should be considered, how DDIs present clinically and its direct or indirect effect on COVID-19 outcomes. Although the underlying biological mechanism triggering those differences in COVID-19 context remains mostly unknown, in the near future, the integration of these different layers of information should promote a better clinical management of COVID-19 patients.

On the electronic healthcare system. This study was only possible due to the digitization of SINOLAVE, an IMSS database that was developed during the 2009 Influenza pandemic and later on refurbished to serve the information needs of the 2019 COVID-19 pandemic. Furthermore, the emergence of virtual randomized clinical trials has shown the value to accelerate results and provide informed guidance to patients [37]. The digitization of electronic health records is possible and should be an overall strategy in resource-constrained settings to provide a data driven approach to public health concerns [38]. Machine learning models and data science can be effectively applied to these settings augmenting the capabilities of the healthcare system. However, our study had several limitations regarding access to data in real-time, and more information directly from the electronic health record. In the future, a more robust pipeline should include a biosurveillance mechanism to estimate the risk of each treatment pattern. 
Conclusion. We observed that the use of the combination of NAIs and cephalosporins as treatment for COVID-19 presented the lowest survival probability by a big margin. It is possible that this effect is observed partly due to a more susceptible population within this group (e.g. higher number of comorbidities), or that the treatment was prescribed after the progression of the disease. Still, we would not recommend the use of this specific combination since it showed the worst survival rate even in those patients without comorbidities, as well as in the younger population. All the other combinations showed much more beneficial outcomes. Surprisingly the use of penicillins alone showed one of the best survival chances for COVID-19 patients in our study, we have not a straightforward explanation for this fact other than the possible prevention of pneumonia which was one of the main complications leading to death (see Figure 2 of Supplementary Material B).

\section{Acknowledgements}

Competing interests. GGA, CAA and ALP declare to work at Amphora Health. ALP declares to hold shares at Amphora Health. CDB is on the scientific advisory boards of AncestryDNA, ArcBio LLC, Etalon DX, Liberty Biosecurity, Personalis, EdenRoc Sciences LLC. CDB and SMG declare to work at Galatea Bio. GGA and ALP are contractors at Galatea Bio. CDB declares to hold shares at Galatea Bio. The remaining authors declare that there is no conflict of interest regarding the publication of this article.

Contributions. ALP designed the study. GGA, CAA, AGG, SGG and ALP performed analysis of data. APO, JJGO, MGA, CDB, JZ, RC, and CAA provided interpretation of the results. GGA and ALP drafted the manuscript, and all authors contributed critically, read, revised and approved the final version.

Funding. Research reported in this publication was partially supported via institutional funds from each participant institution. The funders had no role in study design, data collection and analysis, decision to publish, or preparation of the manuscript.

Ethics approval. This study was approved by the Ethics and Research Committees from the Mexican Institute of Social Security (IMSS), which are certified as Institutional Review Board 
medRxiv preprint doi: https://doi.org/10.1101/2021.12.16.21267866; this version posted December 17, 2021. The copyright holder for this preprint (which was not certified by peer review) is the author/funder, who has granted medRxiv a license to display the preprint in perpetuity.

It is made available under a CC-BY-NC-ND 4.0 International license .

(IRB) in accordance with the Mexican regulation, under protocol numbers R-2021-1912-014, R-2020-785-058.

Data Availability. The data that supports the findings of this study is available for research purposes upon written request, which will be reviewed on a case-by-case basis by IMSS IRB given the submission of a research protocol.

\section{References}

1. Yang, A., Qiu, Q., Kong, X., Sun, Y., Chen, T., Zuo, Y., ... \& Peng, A. (2020). Clinical and epidemiological characteristics of COVID-19 patients in Chongqing China. Frontiers in public health, 8, 244.

2. Zhou P, Yang XL, Wang XG, et al. A pneumonia outbreak associated with a new coronavirus of probable bat origin. Nature 2020;579:270-3.

3. La Torre, G., Massetti, A. P., Antonelli, G., Fimiani, C., Fantini, M., Marte, M., ... \& Mastroianni, C. M. (2020). Anosmia and ageusia as predictive signs of COVID-19 in healthcare workers in Italy: a prospective case-control study. Journal of Clinical Medicine, 9(9), 2870.

4. Centers for Disease Control and Prevention. Coronavirus Disease 2019 (COVID-19).

Information for people who are at higher Risk for Severe Illness. Accessed on April 15, 2020.

5. US Department of Health and Human Services/Centers for Disease Control and Prevention.

Preliminary Estimates of the Prevalence of Selected Underlying Health Condition Among Patients with Coronavirus disease 2019 (COVID-19) United States, February 12-March 28, 2020. Morbidity and Mortality Weekly Report April 3,2020;69:13: 382-386.

6. US Department of Health and Human Services/Centers for Disease Control and Prevention.

Severe outcomes among patients with coronavirus disease 2019 (COVID-19) United States, February 12-March 16, 2020. Morbidity and Mortality Weekly Report March 27,2020;69:12: 343-346. 
7. Wang D, Hu B, Hu C, Zhu F, Liu X, Zhang J, Wang B, Xiang H, Cheng Z, Xiong Y, Zhao Y, Li Y, Wang X, Peng Z. 2020. Clinical Characteristics of 138 Hospitalized Patients With 2019 Novel Coronavirus-Infected Pneumonia in Wuhan, China. JAMA. Feb 7; e201585. doi:10.1001/jama.2020.1585.

8. Gautret P, Lagier JC, Parola P, et al. Hydroxychloroquine and azithromycin as a treatment of COVID-19: results of an open-labeled non-randomized clinical trial. Int J Antimicrob Agents. 2020 Mar 20 :105949. Doi: 10.1016/j.ijantimicag.2020.105949.

9. World Health Organization, WHO (2019), 2019-nCoV outbreak is an emergency of international concern. Available http://www.euro.who.int/en/health-topics/health-emergencies/international-health-regulations /news/news/2020/2/2019-ncov-outbreak-is-an-emergency-of-international-concern.

10. Centers for Disease Control and Prevention (CDC). Emerging SARS-CoV-2 Variants. Updated Jan 22021.

11. Johns Hopkins Coronavirus Resource Center (2021). Mortality Analyses - Johns Hopkins Coronavirus Resource Center. [online] Available at: $<$ https://coronavirus.jhu.edu/data/mortality $>$ [Accessed December 6, 2021].

12. G.T.A. de Vacunación Covid (2020). Priorización inicial y consecutiva para la vacunación contra SARS-CoV-2 en la población mexicana. Recomendaciones preliminares. Salud Pública de México.

13. World Health Organization. COVID-19 Dashboard (https://covid19.who.int/). Accessed Dec $6,2021$.

14. Instituto Mexicano del Seguro Social. Dirección de prestaciones médicas. Algoritmos interinos para el manejo del COVID-19. 7 abril del 2020).

15. Instituto Mexicano del Seguro Social. Dirección de prestaciones médicas. Algoritmos interinos para el manejo del COVID-19. 25 junio del 2020).

16. (Instituto Mexicano del Seguro Social. Dirección de prestaciones médicas. Algoritmos interinos para el manejo del COVID-19. 25 de septiembre del 2020).

17. (Boulware,DR, Pullen MF, Bangdiwala AS, Pastick KA, Lofgren SM, Okafor EC, et al. A randomized trial of hydroxychloroquine as postexposure prophylaxis for Covid-19. New Engl J Med 2020;383;6:517-525.)

18. The RECOVERY Collaborative Group. Effect of hydroxychloroquine in hospitalized patients with Covid-19. New Eng J Med 2020;383;21:2030-2040. 
19. Cavalcanti AB, Zampieri FG, Rosa RG, Azevedo LCP, Veiga VC, Avezum A, et al. Hydroxychloroquine with or without azithromycin in mild-to-moderate Covid-19. New Engl J Med 2020;383;21:2041-2052.

20. Simonovich VA, Burgos Pratx LD, Scibona P, Beruto MV, Vallone MG, Vázquez C, et al. A randomized trial of convalescent plasma in Covid-19 severe pneumonia. N Engl J Med 2020; PlasmAr ClinicalTrials.gov number, NCT04383535. DOI: 10.1056/NEJMoa2031304.

21. Chen P, Nirula A, Heller B, Gottleib RL, Boscia J, Morris J, et al. New Engl J Med 2020;1-9DOI: 10.1056/NEJMoa2029849.

22. Aziz M, Brenner M, Wang P. Therapeutic potential of B-1A cells in COVID-19. Shock 2020;54;5:585-594

23. von Elm, E., Altman, D. G., Egger, M., Pocock, S. J., Gøtzsche, P. C., \& Vandenbroucke, J. P. (2007). The Strengthening the Reporting of Observational Studies in Epidemiology (STROBE) statement: guidelines for reporting observational studies. Lancet, 370, 1453-57.

24. McCaw, Z. R., Tian, L., Vassy, J. L., Ritchie, C. S., Lee, C. C., Kim, D. H., \& Wei, L. J. (2020). How to quantify and interpret treatment effects in comparative clinical studies of COVID-19. Annals of internal medicine, 173(8), 632-637.

25. Wilks, D. S. (2011). Statistical methods in the atmospheric sciences (Vol. 100). Academic press.

26. WHO Director-General's opening remarks at the media briefing on COVID-19-11 March 2020.

27. Guan, W. J., Liang, W. H., Zhao, Y., Liang, H. R., Chen, Z. S., Li, Y. M., ... \& He, J. X. (2020). Comorbidity and its impact on 1590 patients with COVID-19 in China: a nationwide analysis. European Respiratory Journal, 55(5).

28. Richardson, S., Hirsch, J. S., Narasimhan, M., Crawford, J. M., McGinn, T., Davidson, K. W., ... \& Northwell COVID-19 Research Consortium. (2020). Presenting characteristics, comorbidities, and outcomes among 5700 patients hospitalized with COVID-19 in the New York City area. Jama, 323(20), 2052-2059.

29. Salinas-Escudero, G., Carrillo-Vega, M. F., Granados-García, V., Martínez-Valverde, S., Toledano-Toledano, F., \& Garduño-Espinosa, J. (2020). A survival analysis of COVID-19 in the Mexican population. BMC Public Health, 20(1), 1-8.

30. Yang, X., Yu, Y., Xu, J., Shu, H., Liu, H., Wu, Y., ... \& Shang, Y. (2020). Clinical course and outcomes of critically ill patients with SARS-CoV-2 pneumonia in Wuhan, China: a single-centered, retrospective, observational study. The Lancet Respiratory Medicine, 8(5), 475-481.

31. Onder, G., Rezza, G., \& Brusaferro, S. (2020). Case-fatality rate and characteristics of patients dying in relation to COVID-19 in Italy. Jama, 323(18), 1775-1776. 
medRxiv preprint doi: https://doi.org/10.1101/2021.12.16.21267866; this version posted December 17, 2021. The copyright holder for this preprint (which was not certified by peer review) is the author/funder, who has granted medRxiv a license to display the preprint in perpetuity.

It is made available under a CC-BY-NC-ND 4.0 International license .

32. Li, B., Yang, J., Zhao, F., Zhi, L., Wang, X., Liu, L., ... \& Zhao, Y. (2020). Prevalence and impact of cardiovascular metabolic diseases on COVID-19 in China. Clinical Research in Cardiology, 109(5), 531-538.

33. Franceschi, C., Garagnani, P., Parini, P., Giuliani, C., \& Santoro, A. (2018). Inflammaging: a new immune-metabolic viewpoint for age-related diseases. Nature Reviews Endocrinology, 14(10), 576-590.

34. Singh, M. V., Chapleau, M. W., Harwani, S. C., \& Abboud, F. M. (2014). The immune system and hypertension. Immunologic research, 59(1-3), 243-253.

35. Gregor, M. F., \& Hotamisligil, G. S. (2011). Inflammatory mechanisms in obesity. Annual review of immunology, 29, 415-445.

36. Morgan, O. W., Bramley, A., Fowlkes, A., Freedman, D. S., Taylor, T. H., Gargiullo, P., ... \& Fry, A. M. (2010). Morbid obesity as a risk factor for hospitalization and death due to 2009 pandemic influenza A (H1N1) disease. PloS one, 5(3), e9694.

37. Liu, R., Rizzo, S., Whipple, S., Pal, N., Pineda, A. L., Lu, M., ... \& Zou, J. (2021). Evaluating eligibility criteria of oncology trials using real-world data and AI. Nature, 592(7855), 629-633.

38. López-Pineda, A., Rodríguez-Moran, M. F., Álvarez-Aguilar, C., Valle, S. M. F., Acosta-Rosales, R., Bhatt, A. S., ... \& Bustamante, C. D. (2018). Data mining of digitized health records in a resource-constrained setting reveals that timely immunophenotyping is associated with improved breast cancer outcomes. BMC cancer, 18(1), 1-10. 